\title{
Instrumental Ensemble in Russian Music — Timbre Innovations
}

\author{
Nailya Samoylova \\ Music Department \\ Orenburg State Institute of Arts. L. and M. Rostropovich \\ Orenburg, Russia \\ nellja056@gmail.com
}

\begin{abstract}
The article analyzes the genre portrait of ensembles with piano based on the genre of piano quartet in national music. New tendencies appearing in the culture of ensemble playing and characterizing the nature of genre are mentioned. The organic inclusion of chamber in the music of the $21^{\text {st }}$ century, which is the most important component of general-style musical processes, is substantiated. Attention is paid to the timbre representation of ensembles, where an increasing role is played by new principles of sound production on different instruments, a departure from the classical composition, the search for new timbre combinations. The demand for the genre and prospects for its development in the 21 st century are noted.
\end{abstract}

Keywords-genre; chamber-instrumental ensemble; timbre; ensemble with the participation of pianoforte

\section{INTRODUCTION}

The $21^{\text {st }}$ century has already made its own adjustments to the ratio of the art of chamber ensembles and the contemporary community. New tendencies characterizing the life of the genre appears in the culture of ensembles. At the stage of modernity, even in the music of the 20th century, the style polyphony of ensembles with pianos proved to be especially demonstrative. In this situation, on the one hand, there is further development and enrichment of the norms and principles of classical art, and in parallel, there is the growth of radical transformations that deny the time-tested genre and timbre canons. However, in any case, the key is the compositional interpretation of the genre, where the question arises due to the style of the genre and where experimentation finds rationale, primarily in the context of the composer's individual style.

In the music of the $21^{\text {st }}$ century, chamber is still among the most important components of general music styles. So, it actively influences the update of the very phenomenon of the sound image of the ensemble with the participation of the piano. Exactly in such a combination of instruments the timbre sphere itself is easily transformed, exhibiting flexibility and mobility. And it is important to pay attention to some other components. The field of chamber music of the completed century has considerably expanded due to the intensive development of the genres themselves, previously less popular with the composer's practice. In addition, the stylistic interchange turned out to be positive both within the genres of ensemble music (duet, trio, quartet and quintet), as well as quite different chamber spheres with a larger composition of participants. In the timbre representation of ensembles, a new role is played by new principles of sound production on different instruments, which influenced his repertoire.

From the standpoint of the $21^{\text {st }}$ century, it became obvious that there are both dynamics and a departure from the classical composition, connected with the search for new timbre combinations. Often there are some cases when the timbre becomes the dominant means of expressiveness, and searches in the realm of timbre are set as an end in itself Moreover, this happens not only as a result of the composers' enthusiasm for another sound field, for example, electronic music. It is also noted by S. Slonimsky in his article "The Third Avant-Garde and the Way of Music": "The current ultra-sonorous trend is the newest "third avant-garde". To some extent, we are again at the very beginning of musical history, at its origins - his majesty timbre reigns again. However, this timbre is industrially equipped, instrumental and computer-armed. This is not the naive nature itself, but its technically refined 'ultra timbre super complex'" [1].

Let us confirm the observations by referring to such genre as the piano quartet and its role in the musical history of the last centuries. This genre has retained its independence of a composer relevance with the selectivity of the timbre composition. It is known that the piano quartet is not the invention of the previous century. The earliest emergence of this genre samples in European music took place in the first quarter of the 19th century. The quartet, consisting of pianoforte and three string instruments, established itself as a special genre variety that time.

\section{The GenRe Of THE Piano QuARtet IN THE MusicAL HISTORY OF RUSSIA OVER THE LAST CENTURIES}

The birth of the piano quartet in Russia took place later, but it had already acquired full citizenship among a number of other chamber-instrumental creation phenomena to the beginning of the 20th century and become an important global course for its European development. The Russian piano quartet has proved to be a vivid phenomenon in the world history of the genre within a relatively short period of 
time. Its formation was not preceded by the struggle of finding a classical form and principles of instrumental interrelations in the ensemble in Western European music during the 17-18th centuries. The established genre took the classic prototype for granted. At the same time, it announced his romantic nature initially. A new imagery of the Russian piano quartet integrating the most valuable experience of the Viennese classics adapted the features of Russian artistic mentality, folklore and a opportunities for a string trio realization.

It becomes clear why the structure of domestic piano quartets has appeared to be wholly immersed in lyricism with a complex of subjective experiences characterizing it. The latter naturally has not led to the narrowing of the genre ideological imagery.

However, the attitude to the genre of the quartet primarily to the string one - was ambiguous in domestic music at the turn of the 19-20th centuries among composers as well as performers. P. Tchaikovsky being the author of numerous works of various genres never dealt with the piano quartet. On the contrary, the composer's statements indicated that he had been opposed to the musical ensemble for a long time $^{1}$. Nevertheless, there are some facts that indicate the artist's attraction to the chamber music. In the second part of the Second Piano Concert the timbre plan of the composer goes back to the idea of triple soloing, where the function of premiers is give not only to the piano, but to the cello and the violin mostly [3]. The researches also emphasize such appeal to chamber music "... Isn't it a sign of a mournful trio for the violin, cello and piano that Tchaikovsky will devote to the "memory of the great artist"- to Rubinstein Nikolai Grigorievich in 1882?" [4]. Significantly, this ensemble cycle has had a significant impact on the further development of the chamber-instrumental genre. $\mathrm{T}$. Gaidamovich says, "The breadth of the concept, the true symphony, the philosophical depth of the content integrating with an accessible character of the expression - these are the main points, which should be followed by every composer almost obligatory in this kind of compositions after the Tchaikovsky trio" [5].

There are a number of other unclear questions, in particular why a 19-years-old student of Moscow Conservatory S. Taneyev was that very person being asked by Tchaikovsky to do a certain proof-reading work on the publication of the First Piano Concerto (op.23), and why Tchaikovsky put the name of Taneyev as dedicatee on the score of the concert until February 1875 "[6]. Did Taneyev's attraction to chamber music have a significant impact on Tchaikovsky himself? It is known that chamber music was treated by Taneyev as one of the most significant spheres of composer's creation. M. Skrebkova-Filatova says, "Is it possible to imagine Russian chamber music of the second half of the $19^{\text {th }}$ and the beginning of the $20^{\text {th }}$ century without mentioning the name of Sergei Ivanovich Taneyev?" [7].

${ }^{1}$ For example, speaking about the piano trio, he wrote, in particular, in one of the letters to Von Meck, "The thing is that to my ears the acoustic combination of piano with violin or cello is completely incompatible. In this sonority the instruments seem to repel one another..." [2]
This is consistent with the utterance of another modern researcher: "He (Taneyev) became the main figure in the moral and professional terms for musical circles of the old capital at the beginning of the $20^{\text {th }}$ century and he was a person who nearly headed Moscow composers' school" [8].

\section{INSTRUMENTAL ENSEMBLE IN S. TANEYEV'S WORKS}

He gave many creative ideas to the instrumental ensemble as a significant artery. The total volume of works created by Taneyev in this field is unique for the Russian master of the 19 th - beginning of the 20th centuries. The composer determined this sphere as the leading one, where he discovered and mastered various genre branches in domestic opportunities. Asafyev was right to state that it was Taneyev's work where "... Russian chamber instrumental music has finally changed the status of separate more or less successful works, as well as ensembles emerged from the salon music-making to the sphere of higher musical consciousness" [9]. Hence, there is an impressive result and fundamental features of the composer's mentality ${ }^{2}$. Russian national style appears in Taneyev chamber-instrumental works with distinctly individualized form, having shaped on the basis of typical figurative-expressive techniques as characteristic features of Russian psychologized dramaturgy, emerged in P. Tchaikovsky's, A. Borodin's, N. RimskyKorsakov's, M. Mussorgsky's, S. Rachmaninov's, N. Medtner's and N. Myaskovsky's works. The composer's ensemble creativity enriches the picture of Russian national musical character and style. According to G. Lukina "Taneyev's understanding of national elements in music is defined as follows: the word "national" is not the recreation of apparent Russian life phenomena and particular features of Russian character or citing the national musical themes at all ... His (Taneyev's) main objective was to detect the "singing tendencies" as an attribute of the national consciousness in any form ..." [10].

It should be noted that there are significant signs of Taneyev's activity in the field of chamber instrumentalism. Some unpublished writings have preserved in the archives ${ }^{2}$. They indicate serious interest of the composer to different timbre possibilities in the ratio of stringed and keyboard instruments. Working this problem, Taneyev studies the texts of classical works and writes out the most interesting figuration components of the texture.

\footnotetext{
${ }^{2}$ Sonata for violin and piano a-moll (without op., 1911), Trio (for violin, viola and cello D-dur, without op., 1880, and h-moll, without op., 1913; for 2 violins and viola, Op.21, D-dur, 1907, Piano, Op.22, D-dur, 1908; for violin, viola and tenor-viola, Op. 31, Es-dur, 1911), string quartets (Es-dur, without or., 1880; C-dur, without op., 1883; A-dur, without op., 1883; dmoll, without op., 1886, 2nd ed.- 3rd, 1896: 1st, op.4, b-moll, 1890; 2nd, op.5, C-dur, 1895; 4th, op. 11, a-moll, 1891; 5th, op. 13, A-dur, 1903: 6th, op. 19, B-dur, 1905; G-dur, without op., 1905), Piano Quartet op. 20, E-dur 1906; quintets (1st string quintet for 2 violins, viola and 2 cellos, op 14, Cdur1901, 2nd string quintet for 2 violins, 2 violas and violoncello, op.16, Cdur, 1904 Piano quintet, op. 30, g-moll, 1911), Andante for 2 flutes, 2 oboes, 2 clarinets, 2 bassoons and 2 horns (without op., 1883)

${ }^{3}$ The materials of Taneyev's Fund of the Russian State Archive of Literature and Arts (RSALA). "Violin Fingering" and "Violin and Piano Part".
} 


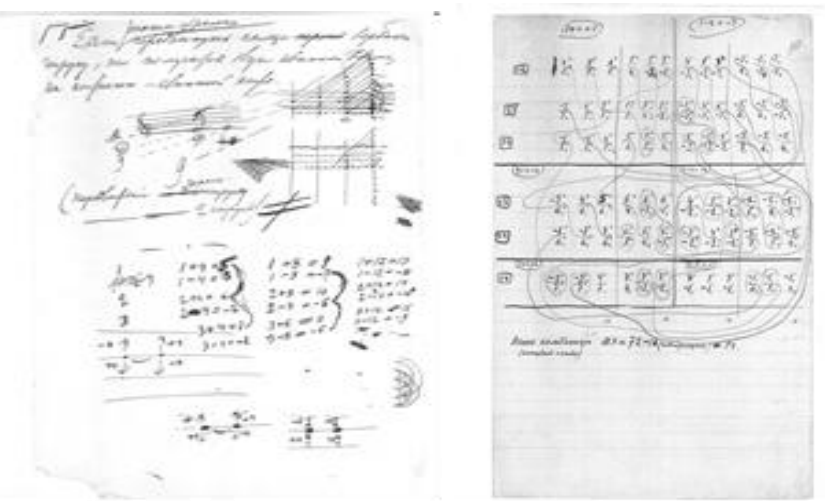

Fig. 1. Violin's inflection (fragment of the manuscript).

The very stage of analytical preparation allowed the composer's ensemble works not only to be aligned with the tone of the time, which implies seeking means of technical and textual re-equipment of musical texts, but also to raise the ensemble genre from the piano level to a higher one, specifically on the level of profound philosophical generalizations.

Taneyev demonstrates constant contact with other genres in chamber creativity. Quartets with the maximum deepening of string instruments content, were followed by other ensemble forms development, adjusting an extensive concept of monumental genres. A consistent creation of string quintets and a piano quartet are the main indications of the following tendency. According to the observations of contemporaries, "a monumental style was alien to Russian musical consciousness" [11]. Taneyev in his way of monumentalizing opposed to the general domestic chamber music direction with a focus on the form figurativeness, strength and shortness. All basic creative ideas and metaphorical spheres typical for a master's symphony, cantata and opera creation will obtain the way in the chamber ensemble cycles within major concepts, which previously were the prerogatives of opera and symphonies in Russian music: deep meditation, drama and spiritual heroism.

For instance, samples of dramatic thematic invention can be found in the first parts of the symphony c-moll and the piano quartet E-dur. "Fig. 2" and "Fig. 3"
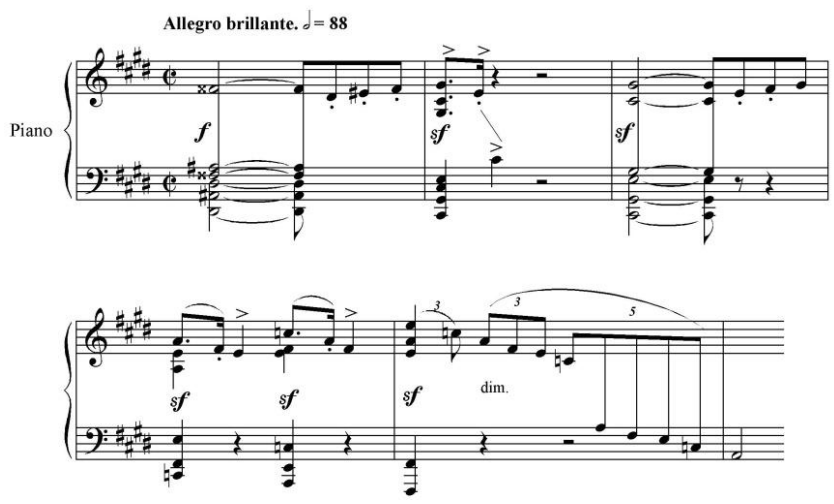

Fig. 2. S. Taneyev. Piano quartet E-dur.

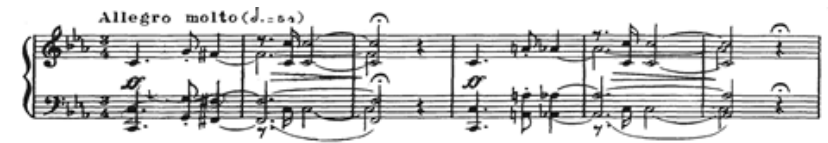

Fig. 3. Symphony c-moll.

\section{The Main Stages of The Evolution of Domestic AND FOREIGN INSTRUMENTAL MUSIC}

In parallel with Taneyev's chamber creativity string ensembles with pianos of other Russian composers, such as M. Ippolitov-Ivanov, V. Zolotarev, V. Zelensky and G. Catuar Towards begin to develop at the turn of the $19^{\text {th }}$ and the $20^{\text {th }}$ centuries. Most of the texts of the piano quartets have signs of the genre normative features deepening. In particular, a steady following the regularities of the sonata and symphonic structures of the cycle is observed, as well as the consolidation of correlating instrumental parts types. Also other style parameters were established as well, which took place in the piano quartet development in the previous century.

Interest of composers of the 20th century to the current genre appears relatively regularly. The very development of the quartet occurs in the context of an individual author's style comprehension of the genre. Various compositions as the piano quartet by V. Denbsky (1942), Sonata-Fantasy for the pianist quartet by M. Gnesin (1945), the piano quartets M. Titsa (1954) and V. Shirinsky (1965) are born.

M. Aranovsky's methodology allows to determine the main directions of the genre development. This methodology regards the instrumental music evolution as a triad: the preservation of the canonical principles of the genre, then an update within the canon, and its new life, outside the canon.

At the same time. it turns out that the style development of the piano quartet in the 19th and 20th centuries resonates with the general evolutionary processes in the instrumental music of these centuries. In Russian music the initial period of the genre development refers to the end of the 19th century and covers the first two decades of the 20th century. For example, the quartet opus organized by M. IppolitovIvanov (1893) at this stage demonstrates a direct connection with the canon of the genre, where the style of the piano Quartet arranged by G. Catoire (1916) is generally canonical. 


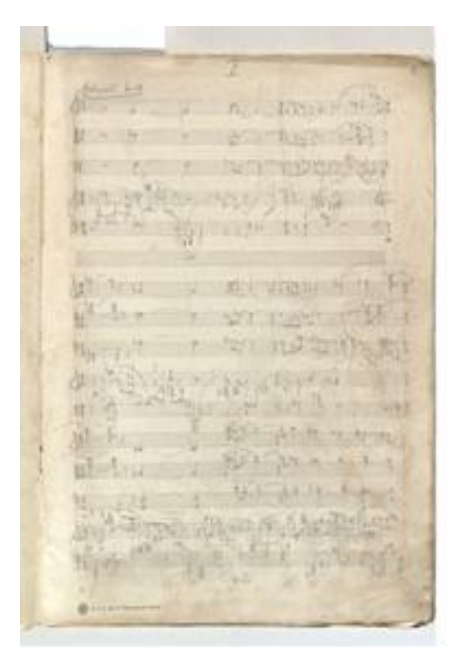

Fig. 4. G. Catuar. Piano quartet a-moll (fragment of the manuscript).

At the same time, the consistency of the principles of monotheism is an example of the presence of certain new features in this work. Along with this, the features of the formation of the chamber composition, where constructive design, from the point of view of the cycle, can be defined as a form "blurred" from part to part, allow to view the piano quartet by $\mathrm{G}$. Catua as a milestone on the way to genre renewal. "Fig. 4"

Closer to the middle of the completed century, the genre is renewed within the framework of the canon, for example, in the V. Denbsky quartet (1942) and M. Gnesin's Sonatafantasy (1945). In the last text, the composer emphasizes the well-known freedom of form, clarifying the name of the work - sonata-fantasy for the piano quartet. In addition, in both scores there is also some innovation in harmonic hearing and in rhythmic structure. The classical composition of the quartet (string trio and piano) is preserved in all the above works created in the first half of the 20th century. In the group of chamber compositions of the last third of the 20th century, the most radical transformations of the genre are seen. The original timbre compositions were introduced into their ensembles - S. Gubaidulina, E. Denisov, A. Schnitke. Among them, only the latter used the traditional composition of the ensemble for three strings and piano. Gubaidulina and Denisov approached the creative decision in a different way.

Both masters create an ensemble for the four instruments, first of all going beyond the timbre canon. So, "Music for harpsichord and percussion instruments from the collection of Mark Pekarsky" Gubaidulina (1971) is a text that resonates with such an important trend as the concert function of percussion instruments, which became especially significant in the sound environment of XX century music. The play was written for drummer Mark Pekarsky and pianist Boris Berman. The basis of its phonosphere is the music of timbres, where the European cembalo, three oriental and Pompeian percussion voices are united Chinese, chang, bian-jun. The author of "Music" aspires to the timbre equilibrium of all participants. Both parts of the composition are realized as a contrast-symmetric movement up (the first part) and down (the second part). The text of the quartet includes two characteristic allusions: the waltz of Chopin cis-moll (in Bian-jun and the Pompeian cymbal), fugues of g-moll from the first volume of the "WellTempered Clavier" J.S. Bach. There was also a new "proposal" from Denisov, who created the musical essay "Pain and Silence" on the verses of O. Mandelstam (1979). The voice of the quartet and the verbal series are now involved in the sound environment of the quartet. Also created an unusual timbre synthesis: mezzo-soprano, clarinet, viola and piano. Such a composition is an example of an individual timbre solution, chosen specifically for this score. Such trends are also observed in the quartet for soprano, flute, viola and harp on Goethe's poems "Mountain Peaks" ("ÜberallenGipfelnistRuh ...") by F. Druzhinin (1994).

At the same time, composers in the 20th century make dominant the idea of not only comparing, but also contrasting timbres. Thus, "Fig. 5" A. Shnitke's piano quartet almost equally presents both timbre-sound ideas: unity and opposition, where a special role is assigned to a keyboard instrument as a leader, often performing the role of an orchestra.

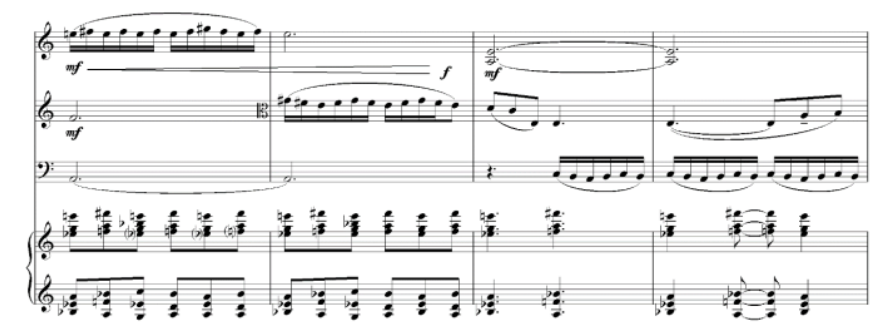

Fig. 5. A. Schnittke. Piano Quartet.

This ensemble composition has a timbre idea, where piano and strings are often treated antagonistically "Fig. 6". Here timbre determinism allowed the composer to dramatically dramatize the idea, in which the point is the idea of conflict - the person and the environment.

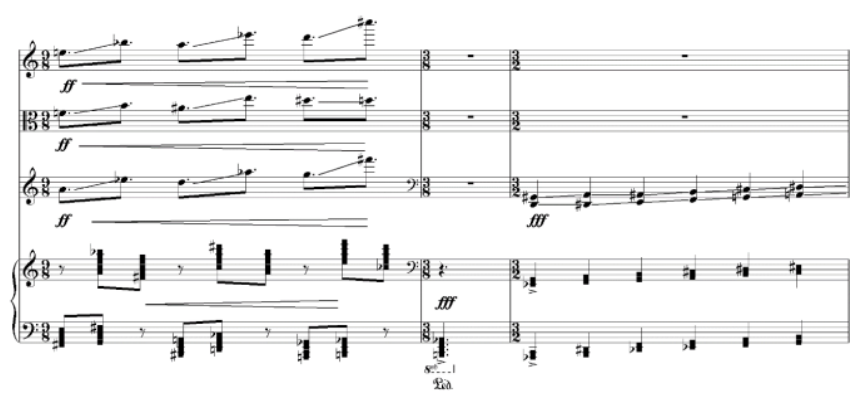

Fig. 6. Piano and strings are often treated antagonistically.

It should also be taken into account that the twentieth century pianism does not so much cultivate the cantilena factor as it goes back to the reproduction of noise and ringing effects (beats on the piano cover or its body, cluster hits on the keyboard, strikes on the strings with fingers, etc.).

Let us emphasize one more remarkable tendency: the chamber-instrumental ensemble by the beginning of the last century was already sufficiently prepared for the sound implementation of new semantic and technological trends. The ensembles were involved in the process of mastering 
almost all style innovations of the era. Because of this, at the beginning of the XX century, the genre is moving noticeably on the musical stage. It was during this period that the foundation of his style and repertoire abundance, observed in our days, was making. The reason for this was the variety of style directions, the tendency to free interpretation of the ensemble and the strongest attraction to a variety of instrumental combinations. In addition, the role of the detailed timbre letter has clearly increased.

The described phenomena took place not only (and sometimes not so much) in the domestic ensemble creativity, but first of all the world chamber music of the first third of the XX century, where the styles were especially varied from classical standards to various forms of experimentation. A number of chamber works of that time have a tendency to a positive vision of the world and of man, which was expressed in the balance of forms and clarified vocabulary ${ }^{3}$. Subjective and romantic specificity manifested itself occasionally, which was sometimes reflected in exclusivetendentious headlines among them: "Accidents" (for the piano quartet) by F. Schmitt (1939). A similar mood was in the quintets: "31 Moments" (for woodwinds, celesta, xylophone, percussion and piano) P. Arma (1951), "14 Ways to Describe the Rain" (flute, clarinet, violin, cello and piano) by W. Eisler (1941).

We should note: the development of domestic chamberinstrumental music of the second half of the XX century has deep connections with the processes that took place in the foreign ensemble creativity. Thus, in Russian music, a similar tendency resonates with the previously mentioned work of E. Denisov ("Pain and Silence" for voice, clarinet, viola and piano (1979), as well as Y. Kasparov ("Landscape, going to infinity" for clarinet, Violin, Cello and Piano (1991), V. Tarnopolsky ("Scenes from Real Life" for soprano, flute, French horn and piano (1995).

Another direction is represented by chamber compositions related to the branch of the early avant-garde and as an example, we give a quartet for violin, clarinet, tenor saxophone and piano A. Webern (1980).

\section{CONCLUSION}

Note that the very field of chamber-instrumental creativity has acquired many special features in the development from romantic imagery to the multiplicity of stylistic manifestations of modernity. Musical compositions for strings and pianos have passed through different phases of evolutionary processes. This affected the presence in the structure of compositions at different levels: the content aspect, instrumental-timbre solutions, rethinking the functional roles of musical instruments-partners, stable and mobile features.

${ }^{3}$ In particular, Two Interludes for Flute, Violin and Piano by J. Ibera, Morning Serenade for Piano and 18 Instruments by F. Poulenc (1929), "Shepherd's Songs" for piano trio B. Martin (1940), Pastoral for flute, violin and piano H. Andrisen (1956), the first pianist quintet T. Bacevich (1952).
In modern composer's work, the demand for a genre is obvious. In particular, it was in the first decade of the $21 \mathrm{st}$ century that a series of ensembles of quartets with the participation of pianoforte born in the walls of large educational institutions arose: the piano quartet of the Musical Pedagogical Institute named after M.M. IppolitovIvanov, as well as similar ensembles in the student version of the Tchaikovsky Moscow State Conservatory - the quartet of piano Credo and quartet of Anno Domini. .

In the current century, interest of pianist composers to ensemble concerts with strings does not require special comments. Moscow pianist and composer N. Mndoyants composed piano quartet (2009) specially for Credo-quartet. The composition has three different parts with the usual tempo contrasts.

The Russian piano quartet itself is not only the past, but also an integral part of today's panorama of chamber genres. The present evidence of his constant renewal is the scores of contemporary composers and interpreters ${ }^{5}$. The young composers A. Besonogov and A. Petaykin (2015), laureates of the International Competition for the Memory of A. Schnittke and S. Richter, turned to the genre of the piano quartet of classical composition.

As we can see: the latest generation of ensembles with the participation of pianos, both stable in terms of timbre representation, and those that accept a variant timbre combination, attests to the great artistic potency of the genre branch itself, which has proved the inexhaustible possibilities of this sphere through the whole course of its historical development.

\section{REFERENCES}

[1] S. M. Slonimsky, The third avant-garde / We play from the beginning. - 2014. - No. 9, p.3.

[2] T. A. Gaidamovich, Russian piano trio: the history of the genre. Questions of interpretation. - M., 1993, p.131.

[3] E. B. Dolinskaya, Piano concert in Russian music of the XX century Research essays. - M.: Publishing House "Composer", 2005, p. 367.

[4] I. Rayskin://WWW.MARIINSKY.RU/PLAYBILL/PLAYBILL/2015/5/ 1/3_2000.

[5] T. A. Gaidamovich, Russian piano trio: the history of the genre. Questions of interpretation. - M., 1993, p.137.

[6] P.E. Weidman S.I., Taneyev and P.I. Tchaikovsky: from the history of relationships / In memory of Sergei Ivanovich Taneyev. 1915-2015 Collection of articles for the $100^{\text {th }}$ anniversary of the death. Moscow: Publishing House "Scientific Library", 2015, p. 7.

[7] M. S. Skrebkova-Filatova, Taneyev - polyphonist and romanticist / In memory of Sergei Ivanovich Taneyev. 1915-2015: Collection of

\footnotetext{
${ }^{4}$ The piano quartet of the MSC Anno Domini was founded in 2007. The quartet includes Mikhail Akinfin (violin), Alexandra Zhelvakova (viola) Anna Burtseva (cello) and Andrei Baranenko (piano).

${ }^{5}$ Sofronov F. "Mood Pictures" for the piano quartet (2005), Karmanov P. "Cambridge music" for the piano quartet (2008), Zhukov S. "Vision" version for flute and piano trio (2009), Akhunov S. Piano Quartet "Dreams of Van Gogh" (2011), Zobnin A. Quartet for flute, clarinet, bassoon and piano (2011), Khrushchev N. "A lot of noise from rage" for flute, violin, cello and piano (2013).
} 
articles for the 100th anniversary of the death. - Moscow: Scientific Library Publishing House, 2015, p.5.

[8] V.N. Grachev, S. Taneyev - A. Pärt and V. Martynov: the line of prophecy in the musical culture of the Fatherland / In memory of Sergei Ivanovich Taneyev. 1915-2015: Collection of articles for the $100^{\text {th }}$ anniversary of the death. - Moscow: Publishing House "Scientific Library", 2015, p.150.

[9] B.V. Asafiev, The Russian music of the $19^{\text {th }}$ and early $20^{\text {th }}$ centuries. 2nd ed. - L.: Music, 1979, p. 222.

[10] G. U. Lukina Taneyev's work in the light of the Russian spiritual tradition: Monograph. M.: Publishing House "Composer", 2015, p.3.

[11] L. P. Sabaneev, Memoirs about Taneyev, Moscow: Classics - XXI, 2003, p. 26. 